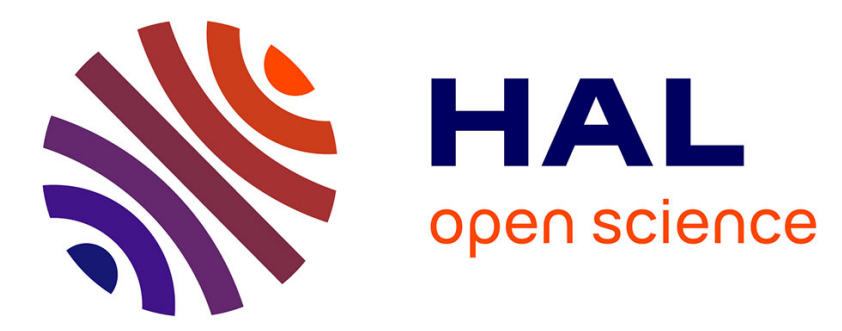

\title{
Ultraviolet optical excitation of near infrared emission of Yb-doped crystalline aluminum oxynitride thin films
}

\author{
Alaa E Giba, P. Pigeat, S. Bruyere, H. Rinnert, F. Mücklich, R. Gago, David
}

Horwat

\section{- To cite this version:}

Alaa E Giba, P. Pigeat, S. Bruyere, H. Rinnert, F. Mücklich, et al.. Ultraviolet optical excitation of near infrared emission of Yb-doped crystalline aluminum oxynitride thin films. Journal of Applied Physics, 2018, 124 (3), pp.033102. 10.1063/1.5040340 . hal-03281654

\section{HAL Id: hal-03281654 \\ https://hal.science/hal-03281654}

Submitted on 8 Jul 2021

HAL is a multi-disciplinary open access archive for the deposit and dissemination of scientific research documents, whether they are published or not. The documents may come from teaching and research institutions in France or abroad, or from public or private research centers.
L'archive ouverte pluridisciplinaire HAL, est destinée au dépôt et à la diffusion de documents scientifiques de niveau recherche, publiés ou non, émanant des établissements d'enseignement et de recherche français ou étrangers, des laboratoires publics ou privés. 


\title{
Ultraviolet Optical Excitation of Near Infrared Emission of Yb- doped Crystalline Aluminum Oxynitride Thin Films
}

\author{
Alaa E. Giba ${ }^{1,2,3}$, P. Pigeat $^{1}$, S. Bruyere ${ }^{1}$, H. Rinnert ${ }^{1}$, F. Müicklich ${ }^{2}$, R.Gago ${ }^{4}$, D. \\ Horwat $^{1 *}$ \\ ${ }^{1}$ Institut Jean Lamour - UMR CNRS 7198- Université de Lorraine, Nancy, France. \\ ${ }^{2}$ Department Materials Science and Engineering, Saarland University, D-66123 Saarbrücken, \\ Germany. \\ ${ }^{3}$ National Institute of Laser Enhanced Sciences, Cairo University, Giza 12613, Egypt \\ ${ }^{4}$ Instituto de Ciencia de Materiales de Madrid, Consejo Superior de Investigaciones Científicas, E- \\ 28049 Madrid, Spain. \\ * contact : $\underline{\text { david.horwat @univ-lorraine.fr }}$
}

\begin{abstract}
$\mathrm{Yb}^{3+}$ ions hold promises for high power emission in the near infrared (NIR). Yet, relevant matrices, comprising mediators to excite $\mathrm{Yb}^{3+}$, have to be found and the optical mechanisms to be studied in details. This is the purpose of this study that reports on the optical excitation and emission mechanisms of NIRphotoluminescence (PL) of Yb-doped crystalline aluminum oxynitride thin films prepared at room temperature using reactive magnetron sputtering. Crystal structure and chemical composition are analyzed by transmission electron microscope (TEM) andRutherford backscattering spectrometry (RBS), respectively. Photoluminescence spectroscopies are used to investigate the excitation and emission mechanisms. NIR emission at $985 \mathrm{~nm}$ is obtained under indirect optical excitation using the $325 \mathrm{~nm}$ line of an $\mathrm{He}-\mathrm{Cd}$ laser,the excitation mechanism is explored by photoluminescence excitation measurement (PLE) and the fine structure of the emitted energy levels is investigated by performing PL measurements at low temperature (LTPL). PLE shows that the host defects play the role of mediatorsto transfer the excitation energy to $\mathrm{Yb}$ ions. This offers different possibilities for the development of multiple excitation channels for $\mathrm{Yb}^{3+}$. Stark splitting of the energy levels of the ${ }^{2} \mathrm{~F}_{5 / 2}$ and ${ }^{2} \mathrm{~F}_{7 / 2}$ transitions is evidenced using LTPL in the 78 to $295 \mathrm{~K}$ range.Electronic transitions are ascribed to experimental emission lines based ongood agreement with theoretical values. Moreover, the activation energies for PL thermal quenching are determined and correspond to the energy difference between highest energy quenched lines and thermally activated "hot lines".
\end{abstract}




\section{Introduction}

Luminescence properties of rare earth-doped wide bandgap materials attract attention due to the development of UV and visible light emitting devices. ${ }^{1-3} \mathrm{~A}$ large bandgap offers high luminescence efficiency and favorable optical properties. III-V semiconductors meet this criterium and exhibit excellent integration with silicon technology. ${ }^{1}$ Thus, many works were directed to the investigation ofthe optical properties of RE-doped III-V compounds, ${ }^{4-7}$ with particular attentions to RE-doped III-nitrides. ${ }^{8-10}$ III-nitrides e.g. (Al, In, Ga)N demonstratedefficient optical activations for a number of RE ions. ${ }^{11} \mathrm{AlN}$ exhibits specific physical/chemical properties such as high thermal conductivity, ${ }^{12-13}$ Excellent piezoelectric coefficient $\mathrm{d}_{33},{ }^{14-16}$ thermal ${ }^{17}$ and chemical stabilities. ${ }^{18}$ Hence, it is well suited for applications in spintronic, ${ }^{19}$ surface acoustic wave ${ }^{20}$ and optoelectronic devices. ${ }^{21}$ The optical activities of several lanthanide elementsincorporated in AIN, covering the light spectrumfrom UV (Gd), ${ }^{22}$ blue $(\mathrm{Ce}, \mathrm{Eu}, \mathrm{Tm}),{ }^{23-24}$ green $(\mathrm{Tb}),{ }^{25}$ yellow (Dy), ${ }^{26} \mathrm{red}(\mathrm{Sm}, \mathrm{Eu})^{26}$ to IR $(\mathrm{Nd}),{ }^{27-28}$ have been investigated.Yet, $\mathrm{Yb}$ has been little considereddespite it holds some advantages. $\mathrm{Yb}^{3+}$ is characterizedby a relatively simple electronic configuration compared to other $\mathrm{RE}^{3+}$. It is considered as two energy levels system consistingof two energy terms ${ }^{2} \mathrm{~F}_{5 / 2}$ and ${ }^{2} \mathrm{~F}_{7 / 2}$. Thanks to this electronic simplicity, $\mathrm{Yb}^{3+}$ placed in different host matrices constitutes a good platform to extract useful information about $f-f$ transitions in $\mathrm{RE}^{3+}$. Hence, it stimulatesextensive investigations, in particular on theoretical calculations. In addition, the energy separation between the ground and excited states of $\mathrm{Yb}^{3+}$ equals $\sim 1.23 \mathrm{eV}$ and related transitions emit photons in the NIR $(\sim 1000 \mathrm{~nm})$. This makes $\mathrm{Yb}^{3+}$ competitive with the well-known, widely used in solid state lightening devices, $\mathrm{Nd}^{3+}$ ion that emits in the same region. Although $\mathrm{Nd}^{3+}$ is widely used, $\mathrm{Yb}^{3+}$ the simpler energy level structureof $\mathrm{Yb}^{3+}$ minimizes the undesirable cross relaxation, the up-conversion and excited-state absorption processes that lead to luminescence quenching in Nd-based systems. ${ }^{29}$ Hence, higher output powers could be obtained by reaching higher concentration of $\mathrm{Yb}$ than $\mathrm{Nd}$ before quenching occurs. In addition, the longer lifetime of the upper excited state of $\mathrm{Yb}^{3+}$ compared to other $\mathrm{RE}^{3+}$ ions provides a better storage of the pump energy, which is desirable in laser applications. However, in contrast with $\mathrm{Nd}^{3+}$ that exhibits several excited states and allows different pumping possibilities, ${ }^{30-31}$ the $\operatorname{simple}{ }^{2} \mathrm{~F}_{5 / 2}$ and ${ }^{2} \mathrm{~F}_{7 / 2}$ structure limits the direct optical excitation of $\mathrm{Yb}^{3+}$ to the related transitions lying in the 920-1050 nm region. ${ }^{32-33}$ Therefore, for better exploiting the optical advantages of $\mathrm{Yb}^{3+}$, it is important to search for new pumping schemes. Hence, much efforts have been spent to find an indirect, more efficient, way to excite $\mathrm{Yb}^{3+}$ by energy transfer via another ion such as $\mathrm{Ce}$, 
$\mathrm{Nd}$.....etc. ${ }^{34-37}$ In this line, this report deals with the indirect optical excitation of $\mathrm{Yb}^{3+}$ ions using AlN defects as mediators for the energy transfer mechanism. This approach avoids the complexity associated to the use of another ion for the energy transfer process to $\mathrm{Yb}^{3+}$. So far, $\mathrm{Yb}$ hasn't been given enough attention as optically active ion in crystalline AlN. ${ }^{28}$ Zanatta, A.R. et al, ${ }^{26,38}$ have screened the effect of thermal annealing on the optical absorption and emission signals of amorphous/nanocrystalline AlN thin films considering $\mathrm{Yb}$ among other $\mathrm{RE}$ ions, whereas Koubaa, $\mathrm{T}$., et $\mathrm{al}^{28}$ theoretically studied the spectral and energy levels of $\mathrm{Yb}$ in crystalline AIN thin films based on cathodluminescence measurements. A dedicated comprehensive study of the optical excitation and emission mechanisms of $\mathrm{Yb}$ in crystalline AlN is still needed, which is the purpose of this report on a systematic study ofYb-doped crystalline AIN thin films in which oxygen incorporation is shown to play a strong role.

\section{Experimental section}

Yb-doped $\mathrm{Al}(\mathrm{O}) \mathrm{N}$ thin films were deposited using RF (Dressler, CESAR RF power generator) balanced reactive magnetron sputtering. A high vacuum pressure of $1 \times 10^{-6} \mathrm{~Pa}$ was obtained by using a turbo molecular pump (BOC EDWARDS EXT 255HI) coupled to a mechanical primary pump. A modified aluminum disk $(99.99 \%$ purity, neyco vacuum \& materials) of 2 inch diameter was used that incorporates a thin bar of metallic $\mathrm{Yb}(99.9 \%$ purity) with differentrelative $\mathrm{Yb} / \mathrm{Al}$ surface areas in order to obtain different $\mathrm{Yb}$ concentrations in the deposited films. Constant gas composition of $\mathrm{Ar}$ and nitrogen with 65\% nitrogen was controlled by adjusting the argon and nitrogen gas flow rates and keeping the total pressure (0.7mtorr) constant using an MKS mass flow controller. A flow rate of oxygen was applied using all-metal gas regulating valveallowingfine control of the oxygen partial pressure before deposition to be $0.1 \times 10^{-6}$ torr. The partial pressure of oxygen has been measured using in situ mass spectrometry. This led to $\sim 7$ at. $\%$ of oxygen in the samples. The compositional analysis wasperformed by Rutherford backscattering spectrometry (RBS) with a $2 \mathrm{MeV} \mathrm{He}$ beam. The experiments were performed with the $5 \mathrm{MV}$ accelerator available at Centro de Microanálisis de Materiales (CMAM) from Universidad Autónoma de Madrid (Madrid, Spain).Due to the lowdetection resolution of RBS for the low content of light elements as well as the overlapping of $\mathrm{O}$ and $\mathrm{N}$ regions, the oxygen concentrations $\sim 6-7$ at.\% was quantified using calibrated EDS coupled to a transmission electron microscope.Silicon (100) substrates have been ultrasonically cleaned in ethanol and fixed at $5 \mathrm{~cm}$ distance from the Al target, facing the target axis. The deposition time was adjusted to reach a thickness close to $200 \mathrm{~nm}$ as monitored using in-situ by laser interferential reflectometry. More details 
about this method and deposition chamber schematic can be found in ref. ${ }^{39}$ The samples underwent apost-deposition rapid thermal annealing (RTA) at $1000{ }^{\circ} \mathrm{C}$ in forming gas (FG) $\left(\mathrm{N}_{2} / \mathrm{H}_{2} \%=90 / 10\right)$ for 5 minutes. The microstructure was investigated by transmission electron microscopy (TEM) in a JEOL ARM 200-Cold equipped with a field-emission gun (FEG) fitted with a GIF Quantum ER.Steady state PL experiments were performed at room and lowtemperatures. Forlow temperature PL measurements (LTPL), the sample of 1 at.\% of Ybwas pasted onto the holder attached to a cold-finger in an opened-cycle $\mathrm{N}_{2}$-cryostat. The sample can be cooleddown to $77 \mathrm{~K}$ and the temperature was controlled by a heat controller by successive steps till $298 \mathrm{~K}$. The cryostat was pumped down to $1 \times 10^{-3}$ torr.Samples were excited by the $325 \mathrm{~nm}$ line of He-Cd laser. For PLE spectroscopy, samples were excited by a xenon arc lamp source. PL emission was analyzed by a cooled silicon-based CCD camera.

\section{Results and discussion}

\section{Compositionand microstructure}

Four thin films of $\mathrm{Yb}$-doped $\mathrm{Al}(\mathrm{O}) \mathrm{N}$ with different $\mathrm{Yb}$ concentrations have been prepared. The composition analyses have been performed using RBS spectrometry to probe the $\mathrm{Yb}, \mathrm{Al}$, $\mathrm{N}$, O elements content. Figure (1) shows the RBS spectrum performed with a $2 \mathrm{MeV} \mathrm{He}^{+}$ beam using a 5MV accelerator. In the RBS spectrum, the regions corresponding to the different elements are labeled ( $\mathrm{Yb}, \mathrm{Al}, \mathrm{Si}, \mathrm{O}, \mathrm{N})$. The content of each element is indicated in the inset table. The composition analysis shows a clear variation in $\mathrm{Yb}$ concentration $(0.05$, $0.5,1$, and 1.5 at.\%)with experimental conditions, N/Al ratio in the $0.91-1.03$ range and incorporation of $\sim 7 \%$ of oxygen in all samples.Chemical analyses were also performed using energy dispersive spectroscopy of X-rays embedded in the TEM and reproduce the evolution obtained using RBS (not shown). For investigating the microstructure,TEM measurements have been performed andwe did not find significant changes in the microstructure upon increasing the $\mathrm{Yb}$ content. Figure (2) shows the TEM and corresponding SAED of a selected sample containing $1 \%$ of $\mathrm{Yb}$. The film exhibits columnar structure and the partial electron diffraction rings with localized bright spots is consistent with the polycrystalline nature of this sample with preferred orientation along [002].

\section{Room temperature Photoluminescence spectroscopy}


The photoluminescence response of the prepared sampleswas measured under excitation by $325 \mathrm{~nm}$. Figure (3a) shows the PL signal of the as-deposited samples of different Yb contents. PL spectra can be divided into two main regions: broad bands in the visible region $(\sim 450-600$ $\mathrm{nm})$ and sharper bands in the NIR $(\sim 900-1050 \mathrm{~nm})$. The bands in visible region are attributed to radiative defects in the AlN matrixas reported for undoped AlN. ${ }^{40}$ No PL signal related to $\mathrm{Yb}^{3+}$ ions have been previously reported in this region. The NIR emission bands are characteristic of $\mathrm{Yb}^{3+}$ ions, usually encountered around (967- $1030 \mathrm{~nm}$ ), as reported elsewhere ${ }^{28,41}$ and are assigned to the optical transitions from ${ }^{2} \mathrm{~F}_{5 / 2}$ to ${ }^{2} \mathrm{~F}_{7 / 2} .{ }^{42-43}$ It is well established that thermal annealing is required to enhance the emissionfrom RE ions in AlN. ${ }^{38}$ Thus, all samples underwent thermal activation process via rapid thermal annealing (RTA) in forming gas (FG) at $1000{ }^{\circ} \mathbf{C} / 5 \mathrm{~min}$. Then the PL of the annealed samples (RTA) were measured using the same excitation wavelength. Figure (3b) shows the PL spectra of RTA samples. It is found that the PL intensity is thereby increased by a factor of 20 or more, depending on the $\mathrm{Yb}$ content. Moreover, the spectral shape is modified.In the as-deposited samples, the visible and NIR bands exhibit symmetrical non-splitting PL shapewith peaks centered around $500 \mathrm{~nm}$ and 987; respectively. In annealed samples, they display asymmetrical splitting intense PL bands centered around $450 \mathrm{~nm}$ and $985 \mathrm{~nm}$. Increasein theoptical emission intensity of RE triggered annealing is a common behavior correlated with the reduction of non-radiative pathways as thermal annealing may locallyrearrangement the structure favoring the development of a less disordered AlN matrix. ${ }^{38}$ The evolution PL intensity from annealed samples with the $\mathrm{Yb}$ content is shown in inset Fig. (3b). The optimum concentration for highest PL intensity is found around 1 at.\%. At relatively low concentration of $\mathrm{Yb}$, the PL intensity increases as the number of emitting ions increase till it reaches a critical concentrationat which nonradiative energy transfer between neighboring RE ions becomes significant. ${ }^{25}$ In addition,increasing the RE contentin AlN leads to degradation in the quality of the matrix, as demonstrated in [40] for $\mathrm{Ce}-\mathrm{Al}(\mathrm{O}) \mathrm{N}$.

\section{Low temperature Photoluminescence and PL quenching mechanism}

Regarding the spectral shape, it is found that the NIR emission of $1 \% \mathrm{Yb}-\mathrm{Al}(\mathrm{O}) \mathrm{N} \_\mathrm{RTA}$ sample, compared to the as-deposited state, consists mainly of well resolved peak located at $985 \mathrm{~nm}$, a shoulder at $970 \mathrm{~nm}$, a small peak at $994 \mathrm{~nm}$ with other small humps observed at 1000, 1007, and $1020 \mathrm{~nm}$, as shown in Fig. (4).In addition, a broad background at the base of the emission spectrum can be observed, which is likely due to overlapping between unresolved spectral lines.In order to better resolve the energy sub-levels in the PL signal, low 
temperature PL (LTPL) was carried out. Figure (5a) shows the PL spectra for Yb-doped $\mathrm{Al}(\mathrm{O}) \mathrm{N}$ sample excited by $325 \mathrm{~nm}$ and measured from $78 \mathrm{k}$ to $295 \mathrm{~K}$. For better contrasting the modifications, the PL spectra for $78 \mathrm{~K}$ and $295 \mathrm{~K}$ are plotted together, see Fig. (5b). While temperature little affects the shape of the visible bands, NIR peaks are much better resolved at low temperature. All lines and bands show increase in intensity from $295 \mathrm{~K}$ down to $78 \mathrm{~K}$ except the small bands indicated by the black square $\mathbf{m}$, as shown in fig (5b). The PL intensity of these two bands is thermally activated (populated), unlike other lines/bands that are thermally quenched.

It is well established that the energy levels of RE ions undergo spectral splitting into "Stark levels" due to coulomb, spin orbital, and crystal field interactions. However the crystal field plays the most significant contribution in this regard, particularly in RE-doped crystalline materials. Upon $\mathrm{RE}^{3+}$ incorporation into crystalline $\mathrm{Al}(\mathrm{O}) \mathrm{N}$ the energy states of $4 f^{n}$ electrons experience a disturbance due to the applied crystal electric field. The influence of this crystal field on the energy levels of the REs ions can be probed by low temperature PL measurements due to the reduction of the thermal motion of the carriers. The strength and number of the splitting levels is depending on the strength of the local crystal field and on the crystal symmetry around the lattice location of the $\mathrm{RE}^{3+}$; respectively. This is the physical reason behind the observed spectral splitting in many $\mathrm{RE}^{3+}$ ions such as $\mathrm{Pr}^{3+},{ }^{44} \mathrm{Sm}^{3+},{ }^{45} \mathrm{Tm}^{3+},{ }^{46}$ and $\mathrm{Nd}^{3+} \cdot{ }^{47}$ It is also relevant for $\mathrm{Yb}^{3+}$ in $\mathrm{GaN} .{ }^{10,41,48}$ However, to the best of our knowledge, there is only one report dealing with theoretical calculation of $\mathrm{Yb}$ in crystalline $\mathrm{AlN}$ based on crystal field theory and supported by cathodoluminescence (CL) data. ${ }^{28} \mathrm{Up}$ to 25 emission lines/shoulders/humps were found andthe authors couldn't explain such complicated CL spectrum by assuming only $\mathrm{Yb}^{3+}$ substituting the $\mathrm{Al}$ site $\left(\mathrm{Yb}_{\mathrm{Al}}\right)$, and hadto consider a formation of $\left(\mathrm{V}_{\mathrm{N}^{-}} \mathrm{Yb}\right)$ defect complex in their calculation.

The careful examination of the PL at 78k reveals only 9 transitions, as shown in Fig. (6a),suggesting that $\mathrm{Yb}^{3+}$ ions are located on a single site, $\mathrm{Yb}_{\mathrm{Al}}$ in our samples. The two spin orbit manifolds ${ }^{2} \mathrm{~F}_{7 / 2}$ and ${ }^{2} \mathrm{~F}_{5 / 2}$ are split into at most $(2 j+1) / 2$ sublevels, resulting in four and three crystal field levels (doublets), respectively. ${ }^{9}$ At least four PL transitions are, therefore, expected if these transitions are considered only from the lowest excited level in ${ }^{2} \mathrm{~F}_{5 / 2}$, and twelve if transitions from other sublevels are also considered, see the schematic diagram of the energy levels in Fig. (6b) and their corresponding values reported in $^{28}$ for $\mathrm{Yb}$ ions substitute the Al-site $\left(\mathrm{Yb}_{\mathrm{Al}}\right)$ in AlN matrix.All the measured PLlinescorrespond to the theoretical calculation with small shifts,except the two small transitions at $1049 \mathrm{~nm}$ and 1080 
nm (correspond to peak 8 and 9in fig. (6a); respectively) that might be related to a different location(s) of $\mathrm{Yb}$, but with a small density of such states based on the very low intensity of related emissions. ${ }^{28}$ The slight shift between the calculated and measured values can be attributed to the difference in crystal field strength between the two studies. It is well established that the local site symmetry, the crystal field strength, and the ligand arrangements significantly modify the energy level values and the transition probabilities from the sublevels. ${ }^{46}$ These parameters are mostly related to the matrix properties for $\mathrm{Yb}$ in different materials as well as in the same material by local structural modifications. Hence, when the local environment around Ybis changed, the strength and the excitation cross section as well as the branching ratio of the transition lines is altered. ${ }^{46}$ Our results reveal that a good control over the growth conditions and subsequent annealing is essential to adjust the positioning of $\mathrm{Yb}$ ions in $\mathrm{Al}(\mathrm{O}) \mathrm{N}$ as well as for activating the emission properties.

Looking at the thermal dependence of emission intensities, two opposite behaviors are found in Fig. (7). Transition bands indicated by black squares $\mathbf{a}$ (one in visible and one in NIR regions) are thermally activated (populated), unlike all other observed transitions, which are thermally quenched (de-populated), fig (5b). The thermal evolution of NIR band a and summed integrated intensities for all thermally quenched lines (transitions 2 to 9) are shown in Fig. ( 7 a). The integrated signal for lines 2 to 9 shows thermal quenching by about $23 \%$ while the NIR band mshows PL enhancement by $30 \%$ with temperature increasing up to 295K. It is widely established, as described above, that the excitation of $4 f-4 f$ transitions in $\mathrm{RE}$ is achieved by energy transfer via a mediator. This mediator can be the host material(e.g. point defects), as in our case, or another ion (e.g. RE or transition metal). PL thermal quenching pathways can be generally proposed through two channels: ${ }^{49-50}$ In the first channel, with increasing the temperature the gained thermal energy is partially absorbed by the excited mediator and leads to dissociation of its carrier before it transfers the excitation energy to the core localized $f-f$ levels of the RE. In this case, the characteristic time of the quenching process should be shorter than the time of energy transfer to the $f-f$ levels. In the second channel, the gained thermal energy is partially absorbed by the generated carriers in the $f-f$ levels and leads to dissociation of these carriers before it recombines. The later can occur by back energy transfer to the mediator or to another defect that subsequently loses the energy either by radiative or nonradiative processes. This requires that the back energy transfer process is faster than $f-f$ recombination process. It is worth mentioning that, any energy mismatch in the energy transfer process can be accommodated by phonon assistance. ${ }^{49-50}$ 
For understanding the quenching mechanism, the quantitative analysis of the PL thermal quenching evolution with temperature is performed using the Arrhenius equation, see equation (1). The thermal dependence of the PL intensity can be generally described by the Arrhenius equation (1)using the single ${ }^{51}$ or double exponential terms ${ }^{52-53}$ :

$I(T)=\frac{I_{0}}{1+c_{1} \operatorname{Exp}\left(-\frac{E_{A 1}}{K_{B} T}\right)+c_{2} \operatorname{Exp}\left(-\frac{E_{A 2}}{K_{B} T}\right)}$,

where $I(T)$ is the PL intensity at the temperature of T, $I_{0}$ is the integrated PL intensity at $78 \mathrm{~K}$, $E_{\mathrm{A} 1}$ and $E_{\mathrm{A} 2}$ are the activation energies, $c_{1}$ and $c_{2}$ are fitting constants and $k_{\mathrm{B}}$ is Boltzmann's constant. Therefore, the exponential decay behavior of $\left(\frac{I_{0}}{I}-1\right)$ versus $\mathrm{T}^{-1}$ can be used as aguide for the Arrhenius fitting.

Figure $(7 \mathrm{~b})$ shows the data along with the best fit to the Arrhenius plot of integrated PL intensity for thermally de-populated peaks 2 to 9 . From the fitting, two activation energies can be estimated, $\mathrm{E}_{\mathrm{a} 1}=11.1 \mathrm{meV}$ and $\mathrm{E}_{\mathrm{a} 2}=1200 \mathrm{meV}$. In order to understand the physical meaning behind the two activation energies, the approach proposed $\mathrm{in}^{52}$ can be used. The authors noticed that the thermal quenching in the PL lines of $\mathrm{Er}$ in $\mathrm{GaN}$ is accompanied with thermal activation (population) of other lines called "hot lines". In addition, they found that the estimated activation energy is very close to the energy mismatch (energy displaced) between hot and quenched lines. Following the same approach in our case, it is found that the energy displaced between the transition of highest energy within the quenched lines, peak 2 at $981.7 \mathrm{~nm}(1262 \mathrm{meV})$, and the thermally activated lines (a) at $972.2 \mathrm{~nm}(1274.6 \mathrm{meV})$ and $500 \mathrm{~nm}$ (2479 eV) equals 12.2 and $1217 \mathrm{meV}$, respectively. It is very consistent with the estimated activation energies $\mathrm{Ea}_{1}$ and $\mathrm{Ea}_{2}$, respectively.This infers that the thermal quenching of $\mathrm{Yb}^{3+}$ NIR emission in our samples occurs via energy transfer to thermally populated levels (a) emitting at $500 \mathrm{~nm}$ and $972.2 \mathrm{~nm}$. Hence, it can be considered that part of the population of these two levels ( $\boldsymbol{\square})$ is enhanced by phonon-assisted energy transfer from the quenched PL lines in NIR region. 


\section{Photoluminescence excitation (PLE) and excitation mechanisms}

Understanding the origin of this NIR emission requires information about the excitation mechanism of $\mathrm{Yb}^{3+}$. In our case, intense NIR emission from $\mathrm{Yb}^{3+}$ is obtained by $325 \mathrm{~nm}$ excitation despite, as mentioned, $\mathrm{Yb}^{3+}$ has no known absorption band in the UV-Visible regions. This evidences an efficient indirect excitation from the host to $\mathrm{Yb}^{3+}$ ions. Moreover, as the $325 \mathrm{~nm}$ is fairly below the bandgap energy of AlN $(\sim 210 \mathrm{~nm})$, this confirms that the energy transfer from AlN to $\mathrm{Yb}^{3+}$ is mediated by matrix defects located in the bandgap.

In order to probe the excitation mechanisms, PLE measurements have been carried out by monitoring the PL peak at $985 \mathrm{~nm}$.Figure (8) shows the detected PLE spectrum which exhibits two bands located at photon energies ( 3.9 and $4.8 \mathrm{eV})$. It is worth to mention that the positions of these bands are very close to the PLE bands positions of $\mathrm{Ce}$-doped $\mathrm{Al}(\mathrm{O}) \mathrm{N}$ reported in our previous work. ${ }^{54}$ Hence, the assignment for the PLE bands in Yb-doped $\mathrm{Al}(\mathrm{O}) \mathrm{N}$ can be done tothe light of the previous assignment of the PLE of Ce-doped $\mathrm{Al}(\mathrm{O}) \mathrm{N}$ samples. Based on that, these bands can be ascribed to the host defects, more precisely to defect complexes involving Al-vacancy with oxygensubstituting nitrogen.However, in the present PLE, the band around $3.9 \mathrm{eV}$ exhibits much lower relative intensity than the band at 5 $\mathrm{eV}$ while in the case ofCe-doped $\mathrm{Al}(\mathrm{O}) \mathrm{N}$, the twobands have comparable intensities. The higher intensity of the $3.9 \mathrm{eV}$ band in Ce caseis explainedbythe overlapping between the $\mathrm{Ce}^{3+}$ and $\left(\mathrm{V}_{\mathrm{Al}}-\mathrm{O}_{\mathrm{N}}\right)$ defect complex absorption bands.

From electronic structure point of view, Berzina, et $\mathrm{al}^{55}$ reported on the origin of the luminescence from AIN involving two types of defects associated with oxygen; $\mathrm{V}_{\mathrm{Al}}-\mathrm{O}_{\mathrm{N}}$ defect complexes and separate $\mathrm{O}_{\mathrm{N}}$ defect. The authors proposed excitation and emission mechanisms based on exciting $\mathrm{V}_{\mathrm{Al}}-\mathrm{O}_{\mathrm{N}}$ defect (located at around $1.2 \mathrm{eV}$ above the valence band) to its excited state, probably situated close to the conduction band. This isfollowed by electron transfer to a separate $\mathrm{O}_{\mathrm{N}}$ defect located around $4.3 \mathrm{eV}$ above the valence band of AlN. $\mathrm{UV} /$ Visible emission $(\sim 3.1 \mathrm{eV} \approx 400 \mathrm{~nm})$ can be subsequently be detected due to a radiative transition from the separate $\mathrm{O}_{\mathrm{N}}$ defect to $\mathrm{V}_{\mathrm{Al}}-\mathrm{O}_{\mathrm{N}}$ defect complex. ${ }^{56} \mathrm{In}$ the same direction Shi, S.-C., et $\mathrm{al}^{56}$ based on PLE measurements reported on a possible additional excitation pathway from $\mathrm{V}_{\mathrm{Al}}-\mathrm{O}_{\mathrm{N}}$ defect complex level to the separateO $\mathrm{O}_{\mathrm{N}}$ which is probably responsible for absorption at $3.4 \mathrm{eV}$ and emission around $3.2 \mathrm{eV}$. Moreover, Yan, Q., et al. ${ }^{57}$ precisely separated the $\mathrm{V}_{\mathrm{Al}}-\mathrm{O}_{\mathrm{N}}$ defect complexes into two types of complexes $\left(\mathrm{V}_{\mathrm{Al}}-\mathrm{O}_{\mathrm{N}}\right)^{2-}$ and $\left(\mathrm{V}_{\mathrm{Al}}{ }^{-}\right.$ $\left.2 \mathrm{O}_{\mathrm{N}}\right)^{1-}$ depending on the oxygen concentration that give rise to an absorption around $3.9 \mathrm{eV}$ 
due to electronic transitions $\left.\left[\left(\mathrm{V}_{\mathrm{Al}}-\mathrm{O}_{\mathrm{N}}\right)^{2-}=>\left(\mathrm{V}_{\mathrm{Al}}-\mathrm{O}_{\mathrm{N}}\right)^{1-}+\mathrm{e}\right)\right]$ and $4.7 \mathrm{eV}$ due to electronic transitions $\left[\left(\mathrm{V}_{\mathrm{Al}}-2 \mathrm{O}_{\mathrm{N}}\right)^{1-}=>\left(\mathrm{V}_{\mathrm{Al}}-2 \mathrm{O}_{\mathrm{N}}\right)^{0}+\mathrm{e}\right]$.

Thus, from the above, three possible excitations routes based on $\mathrm{V}_{\mathrm{Al}}-\mathrm{O}_{\mathrm{N}}$ defect complexes can be summarized, see the schematic diagram Fig. (9). The first (I) from $\mathrm{V}_{\mathrm{Al}}-\mathrm{O}_{\mathrm{N}}$ level to its excitation state near to the band gap, which represents the electronic transitions $\left[\left(\mathrm{V}_{\mathrm{Al}}-2 \mathrm{O}_{\mathrm{N}}\right)^{1-}\right.$ $\left.\Rightarrow\left(\mathrm{V}_{\mathrm{Al}}-2 \mathrm{O}_{\mathrm{N}}\right)^{0}+\mathrm{e}\right]$ with absorption energy of $4.7 \mathrm{eV}$. The Second (II)from $\mathrm{V}_{\mathrm{Al}}-\mathrm{O}_{\mathrm{N}}$ level to its excitation state due to electronic transitions $\left.\left[\left(\mathrm{V}_{\mathrm{Al}}-\mathrm{O}_{\mathrm{N}}\right)^{2-}=>\left(\mathrm{V}_{\mathrm{Al}}-\mathrm{O}_{\mathrm{N}}\right)^{1-}+\mathrm{e}\right)\right]$ with absorption energy of $3.9 \mathrm{eV}$. The Third (III) from $\mathrm{V}_{\mathrm{Al}}-\mathrm{O}_{\mathrm{N}}$ level to separate $\mathrm{O}_{\mathrm{N}}$ level with absorption of $3.4 \mathrm{eV}$ photons. This shows the important role that can be played by $\mathrm{V}_{\mathrm{Al}}-\mathrm{O}_{\mathrm{N}}$ defect complexes in the optical behavior of $\mathrm{Al}(\mathrm{O}) \mathrm{N}$ matrix. This role has beenexploited to open indirect efficient excitation pathway to $\mathrm{Mn}^{2+}$-doped AlN for red light emitting phosphors as reported in $^{58}$ and more recently in our work with Ce-doped AlN for blue light emission phosphors ${ }^{54}$ In the same line, as $325 \mathrm{~nm}(\sim 3.81 \mathrm{eV})$ is used in the present study, the second excitation route is likely consistent with this absorption energy. Thus, the $\mathrm{V}_{\mathrm{Al}}-\mathrm{O}_{\mathrm{N}}$ defect complexes act as donoracceptor pairsexcited by $325 \mathrm{~nm}$ light to its excited level $\left(\mathrm{V}_{\mathrm{Al}}-\mathrm{O}_{\mathrm{N}}\right)^{1-} \cdot{ }^{22,57}$ After relaxation, part of the absorbed energycan be emitted in the UV/Visible region ${ }^{59}$ and part can be efficiently transferred to $\mathrm{Yb}^{3+}$ ions emitting around $985 \mathrm{~nm}$ upon relaxation.

\section{Conclusion}

Crystalline $\mathrm{Yb}$-doped $\mathrm{Al}(\mathrm{O}) \mathrm{N}$ thin filmshavebeen preparedwith different Ybcontentsmeasured using RBS. The crystal and the microstructure have been analyzed by XRD and TEM techniques.NIR emission at $985 \mathrm{~nm}$ was obtained from the prepared samples under indirect excitation by $325 \mathrm{~nm}$ wavelength. The NIR emission is assigned to the typical ${ }^{2} \mathrm{~F}_{5 / 2}$ and ${ }^{2} \mathrm{~F}_{7 / 2}$ transitions in $\mathrm{Yb}^{3+}$ ions. The optimum $\mathrm{Yb}$ concentration giving highest PL intensity is determined to be 1 at.\%. Post-deposition annealing is essential to improve the emission intensity.The indirect excitation of $\mathrm{Yb}$ ions is proposed to proceedthrough host defects as evidenced by PLE. The fine structure of the $\mathrm{Yb}$ energy levels has been obtained using low temperature PL measurements and the different contributions of this fine structure arein good agreement with theoretical calculation for $\mathrm{Yb}_{\mathrm{Al}}$ in AlN.In addition, quantitative analysis of the thermal dependency of emission intensityis in good agreement with quenching via back energy transfer to thermal populated levels. This dedicated study providesnew details about the optical behavior of $\mathrm{Yb}$ in aluminum-based oxynitride materials and proposes a way to indirectly excite $\mathrm{Yb}$ ions without the need of a RE mediator. This could serve as a platform 
for the development of future solidstate lighting devices and better engineering of $\mathrm{Yb}$ emission in NIR region.

\section{Acknowledgments}

A.E. Giba thanks Erasmus mundus scholarship that financially funded this work within the DocMASE program. He also thanks the "Universitéfranco-allemande" (UFA) for supporting his travel and stay to Saarland University within the PhD-track in Materials Science and Engineering.Financial support from grant P2013/MIT-2775 (ComunidadAutónoma de Madrid, Spain) is greatly acknowledged.

\section{References}

A. J. Kenyon, PROGQUANT ELECTRON26, 225 (2002).

W. M. Jadwisienczak, H. J. Lozykowski, A. Xu, and B. Patel, J. Electron. Mater. 31, 776 (2002). A. J. Steckl, J. C. Heikenfeld, L. Dong-Seon, M. J. Garter, C. C. Baker, W. Yongqiang, and R. Jones, J. Electron. Mater.8, 749 (2002).

H. Ennen, G. Pomrenke, and A. Axmann, J. Appl. Phys. 57, 2182 (1985).

T. Ishiyama, K. Murakami, K. Takahei, and A. Taguchi, J. Appl. Phys. 82, 4457 (1997).

M. Godlewski, A. Kozanecki, K. Karpińska, K. Świątek, J. P. Bergman, and B. Monemar, J. Alloys Compd. 225, 564 (1995).

H. J. Lozykowski, A. K. Alshawa, and I. Brown, J. Appl. Phys. 76, 4836 (1994).

K. Lorenz, E. Alves, S. Magalhães, M. Peres, T. Monteiro, A. Kozanecki, and M. E. G. Valerio, J. Phys. Conf. Ser.249, 012053 (2010).

W. M. Jadwisienczak and H. J. Lozykowski, Opt. Mater. 23, 175 (2003).

M. Dammak, S. Kammoun, R. Maalej, T. Koubaa, and M. Kamoun, J. Alloys Compd. 432, 18 (2007).

K. Lorenz, E. Alves, F. Gloux, and P. Ruterana, in Rare Earth Doped III-Nitrides for Optoelectronic and Spintronic Applications, edited by K. O'Donnell and V. Dierolf (Springer Netherlands, Dordrecht, 2010), p. 25.

G. Pezzotti, I. Kamada, and S. Miki, J. Eur. Ceram. Soc. 20, 1197 (2000).

F. Miyashiro, N. Iwase, A. Tsuge, F. Ueno, M. Nakahashi, and T. Takahashi, IEEE Trans. Compon. Packag. Manuf. Technol. 13, 313 (1990).

K. Giannelli, L. Giovannini, E. Verona, and G. Socino, Prog. IEEE Ultrason. Symp.1996, p. 289

U. Mastromatteo and F. F. Villa, Sens. Actuator B-Chem. 179, 319 (2013).

M. Zhang, J. Yang, C. Si, G. Han, Y. Zhao, and J. Ning, Micromachines 6, 1236 (2015).

J.-p. Meng, X.-p. Liu, Z.-q. Fu, X.-j. Wang, and L. Hao, Appl. Surf. Sci. 347, 109 (2015).

X. D. Wang, U. Mazur, K. W. Hipps, and J. T. Dickson, Thin Solid Films 240, 45 (1994).

C.-w. Zhang, J. Appl. Phys. 111, 043702 (2012).

H. L. Kao, W. C. Chen, C. Wei-Cheng, L. Hui-Feng, C. Tzu Chieh, L. Chung Yi, Y. T. Lin, J. I. Chyi, and C. H. Hsu, Jpn. J. Appl. Phys. 47, 124 (2008).

Y. Taniyasu, M. Kasu, and T. Makimoto, Natur 441, 325 (2006).

T. Kita, Y. Ishizu, K. Tsuji, Y. Harada, Y. Chigi, T. Nishimoto, H. Tanaka, M. Kobayashi, T. Ishihara, and H. Izumi, J. Appl. Phys. 117, 163105 (2015).

H. J. Lozykowski, W. M. Jadwisienczak, A. Bensaoula, and O. Monteiro, Microelectron. J. 36, 453 (2005). 
T.-C. Liu, H. Kominami, H. F. Greer, W. Zhou, Y. Nakanishi, and R.-S. Liu, Chem. Mater.24, 3486 (2012).

W. Wang, P. Zhang, X. Wang, X. Lei, H. Ding, and H. Yang, RSC Adv. 5, 90698 (2015).

R. Weingärtner, O. Erlenbach, A. Winnacker, A. Welte, I. Brauer, H. Mendel, H. P. Strunk, C. T. M. Ribeiro, and A. R. Zanatta, Opt. Mater. 28, 790 (2006).

A. T. Wieg, M. J. Grossnickle, Y. Kodera, N. M. Gabor, and J. E. Garay, Appl. Phys. Lett. 109, 121901 (2016).

T. Koubaa, M. Dammak, M. Kammoun, W. M. Jadwisienczak, H. J. Lozykowski, and A. Anders, J. Appl. Phys. 106, 013106 (2009).

P.-H. Haumesser, R. Gaumé, B. Viana, and D. Vivien, J. Opt. Soc. Am. B 19, 2365 (2002).

M. Li, Z. H. Hao, X. N. Peng, J. B. Li, X. F. Yu, and Q. Q. Wang, Opt. Express 18, 3364 (2010).

W. Luo, J. Liao, R. Li, and X. Chen, PCCP 12, 3276 (2010).

A. Yoshikawa, G. Boulon, L. Laversenne, H. Canibano, K. Lebbou, A. Collombet, Y. Guyot, and T. Fukuda, J. Appl. Phys. 94, 5479 (2003).

F. Rivera-López, P. Babu, C. Basavapoornima, C. K. Jayasankar, and V. Lavín, J. Appl. Phys. 109, 123514 (2011).

Q. Wang, J. Qiu, Z. Song, Z. Yang, Z. Yin, D. Zhou, and S. Wang, J. Am. Ceram. Soc. 99, 911 (2016).

K. S. Kumar, C. Lou, A. G. Manohari, C. Huihui, and D. Pribat, RSC Adv. 7, 24674 (2017).

L. Zhou, P. A. Tanner, L. Ning, W. Zhou, H. Liang, and L. Zheng, J. Phys. Chem. A 120, 5539 (2016).

F. Artizzu, A. Serpe, L. Marchio, M. Saba, A. Mura, M. L. Mercuri, G. Bongiovanni, P. Deplano, and F. Quochi, J. Mater. Chem. C 3, 11524 (2015).

A. R. Zanatta, J. Phys. D: Appl. Phys. 42, 025109 (2009).

A. E. Giba, P. Pigeat, S. Bruyère, T. Easwarakhanthan, F. Mücklich, and D. Horwat, Thin Solid Films 636, 537 (2017).

J. Sun, J. Wu, H. Ling, W. Shi, Z. Ying, and F. Li, Phys. Lett. A 280, 381 (2001).

T. Koubaa, M. Dammak, M. Kammoun, W. M. Jadwisienczak, and H. J. Lozykowski, J. Alloys Compd. 496, 56 (2010).

M. Castaing, F. Balembois, P. Georges, T. Georges, K. Schaffers, and J. Tassano, Lasers and applications in Science and Engineering 2008 (SPIE), p. 8.

S. Yiou, F. Balembois, K. Schaffers, and P. Georges, Appl. Opt. 42, 4883 (2003).

J. B. Gruber, B. Zandi, H. J. Lozykowski, W. M. Jadwisienczak, and I. Brown, J. Appl. Phys. 89, 7973 (2001).

J. B. Gruber, B. Zandi, H. J. Lozykowski, and W. M. Jadwisienczak, J. Appl. Phys. 91, 2929 (2002).

J. B. Gruber, U. Vetter, H. Hofsäss, B. Zandi, and M. F. Reid, Phys.Rev.B 70, 245108 (2004).

J. B. Gruber, G. W. Burdick, U. Vetter, B. Mitchell, V. Dierolf, and H. Hofsäss, Opt. Mater. Express 2, 1176 (2012).

T. Kallel, M. Dammak, J. Wang, W. M. Jadwisienczak, J. Wu, and R. Palai, J. Alloys Compd. 609, 284 (2014).

H. J. Lozykowski, Phys.Rev.B 48, 17758 (1993).

H. J. Lozykowski and W. M. Jadwisienczak, phys. status solidi (b)244, 2109 (2007).

C. Ma, Y. Cao, X. Shen, Z. Wen, R. Ma, J. Long, and X. Yuan, Opt. Mater. 69, 105 (2017).

V. X. Ho, T. V. Dao, H. X. Jiang, J. Y. Lin, J. M. Zavada, S. A. McGill, and N. Q. Vinh, Sci. Rep.7, 39997 (2017).

Y. Fang, L. Wang, Q. Sun, T. Lu, Z. Deng, Z. Ma, Y. Jiang, H. Jia, W. Wang, J. Zhou, and H. Chen, Sci. Rep.5, 12718 (2015).

A. E. Giba, P. Pigeat, S. Bruyere, H. Rinnert, F. Soldera, F. Mücklich, R. Gago, and D. Horwat, ACS Photonics 4, 1945 (2017).

B. Berzina, L. Trinkler, J. Sils, and K. Atobe, Radiat Eff. Defects Solids 157, 1089 (2002). 

Berzina, Appl. Phys. Lett. 89, 163127 (2006). X.-J. Wang, R.-J. Xie, B. Dierre, T. Takeda, T. Suehiro, N. Hirosaki, T. Sekiguchi, H. Li, and Z. Sun, Dalton Trans. 43, 6120 (2014).

D. Chen, J. Wang, D. Xu, and Y. Zhang, Vacuu 83, 865 (2009). 


\section{Figure captions}

Figure 1: RBS fitting data for the prepared $\mathrm{Yb}$-doped $\mathrm{Al}(\mathrm{O}) \mathrm{N}$ samples at different $\mathrm{Yb} \%$. Inset table is the elemental quantitative values.

Figure 2: a) TEM image and b) the corresponding SAED pattern of $1 \%$ Yb-doped $\mathrm{Al}(\mathrm{O}) \mathrm{N}$ thin film.

Figure 3: PL spectra of $\mathrm{Yb}$-doped $\mathrm{Al}(\mathrm{O}) \mathrm{N}$ of different $\mathrm{Yb} \%$ for a) as-deposited and $\mathrm{b}$ ) annealed samples. Inset in b): PL intensity of the NIR fundamental peak at $985 \mathrm{~nm}$ as a function of $\mathrm{Yb} \%$.

Figure 4: Zoom in NIR PL spectra of as-deposited and annealed $1 \%$ Yb-doped $\mathrm{Al}(\mathrm{O}) \mathrm{N}$ samples.

Figure 5: a)PL spectra of $1 \%$ Yb-doped $\mathrm{Al}(\mathrm{O}) \mathrm{N}$ film for different temperatures from $78 \mathrm{~K}$ to $295 \mathrm{~K} . \mathrm{b})$ is the $\mathrm{PL}$ of $1 \% \mathrm{Yb}$-doped $\mathrm{Al}(\mathrm{O}) \mathrm{N}$ sample carried out at $78 \mathrm{~K}$ and $295 \mathrm{~K}$. The excitation wavelength is $325 \mathrm{~nm}$.

Figure 6: a) Zoom in for the NIR emission carried out at $78 \mathrm{~K}$. b) Calculated energy levels diagram for $\mathrm{Yb}^{3+}$ ions in $\mathrm{Al}$ substitutional site $\left(\mathrm{Yb}_{\mathrm{Al}}\right)$ in $\mathrm{AlN}$ (on left). The theoretical (Theo.) and experimental (Exp.) transition lines positions (table on right).

Figure 7: a) Normalized PL as a function of temperature for band number 1 and integrated intensity for lines from 2 to 9 in fig $(10 \mathrm{a}) . \mathrm{b})\left(\frac{I_{0}}{I(T)}-1\right)$ versus $\mathrm{T}^{-1}$ for Arrhenius guiding of $1 \%$ Yb-doped $\mathrm{Al}(\mathrm{O}) \mathrm{N}$ sample.

Figure 8: PLE spectrum of annealed $1 \% \mathrm{Yb}$-doped $\mathrm{Al}(\mathrm{O}) \mathrm{N}$ samples compared with the PLE of annealed $1 \% \mathrm{Ce}$-doped $\mathrm{Al}(\mathrm{O}) \mathrm{N}$ (reported in ref. ${ }^{54}$ ) monitored at emission wavelengths 985 $\mathrm{nm}$ and $500 \mathrm{~nm}$; respectively.

Figure 9: Schematic diagram representing the proposed excitation and emission processes of $\mathrm{Yb}$ in $\mathrm{Al}(\mathrm{O}) \mathrm{N}$ host. I, II and III are the excitation routes at excitation energies $4.7 \mathrm{eV}, 3.9 \mathrm{eV}$, and $3.4 \mathrm{eV}$; respectively. 
Figure 1

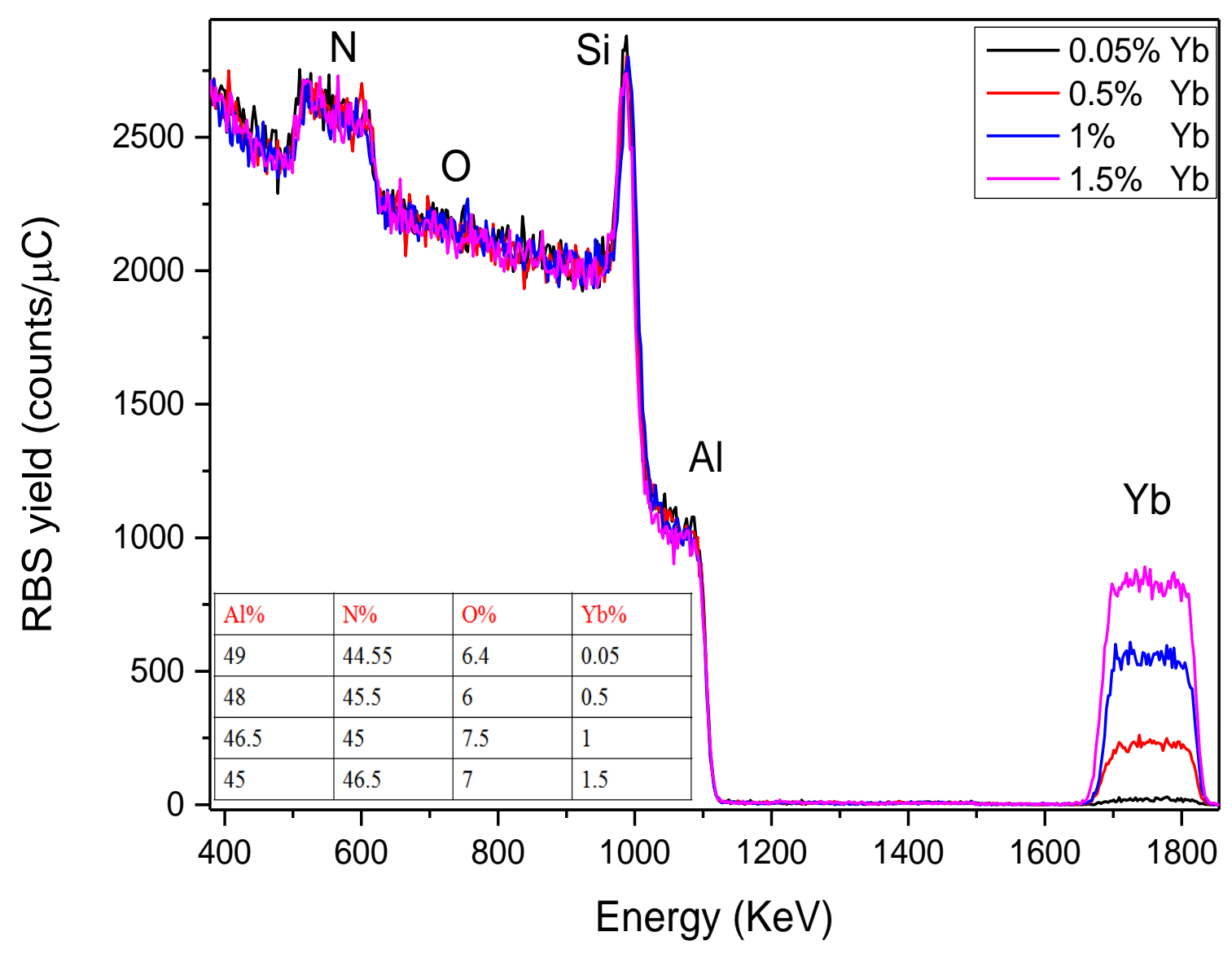


Figure 2

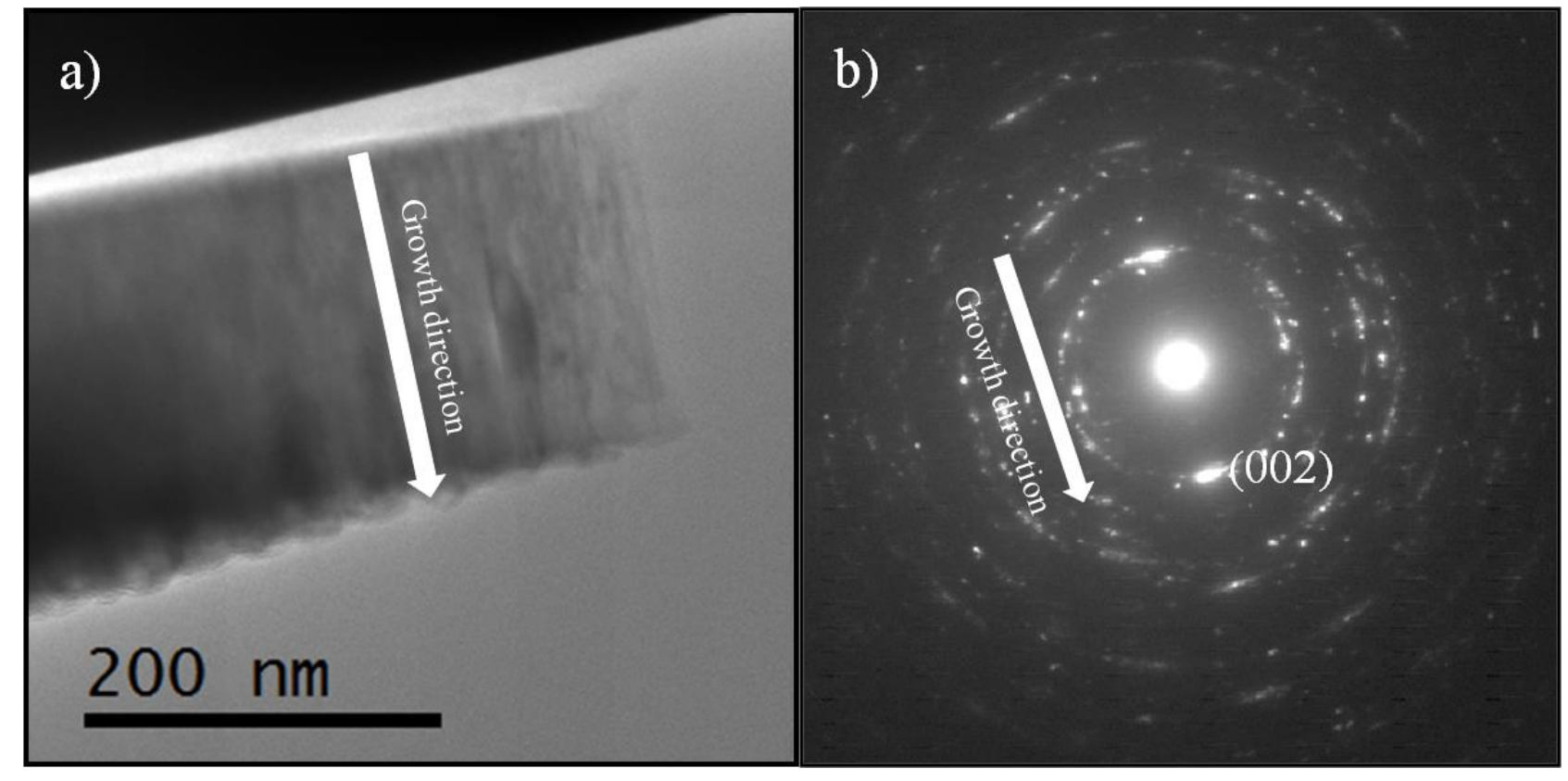


Figure 3

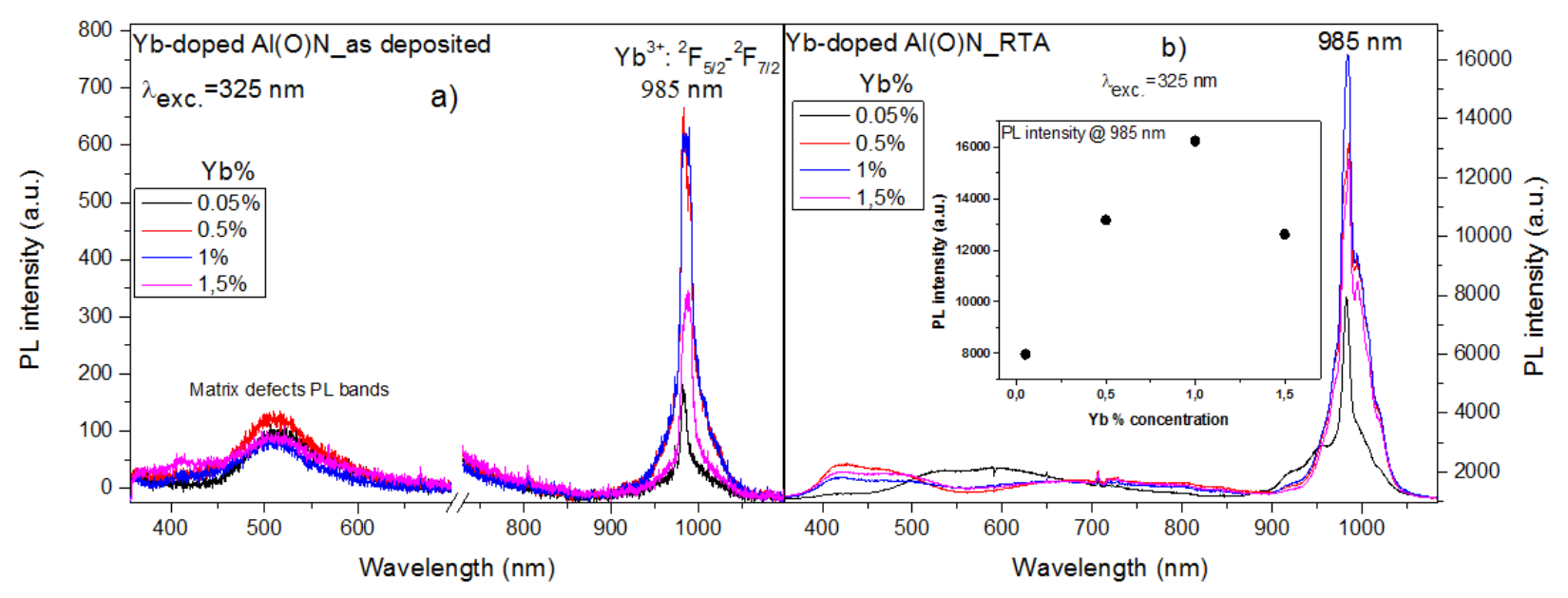


Figure 4

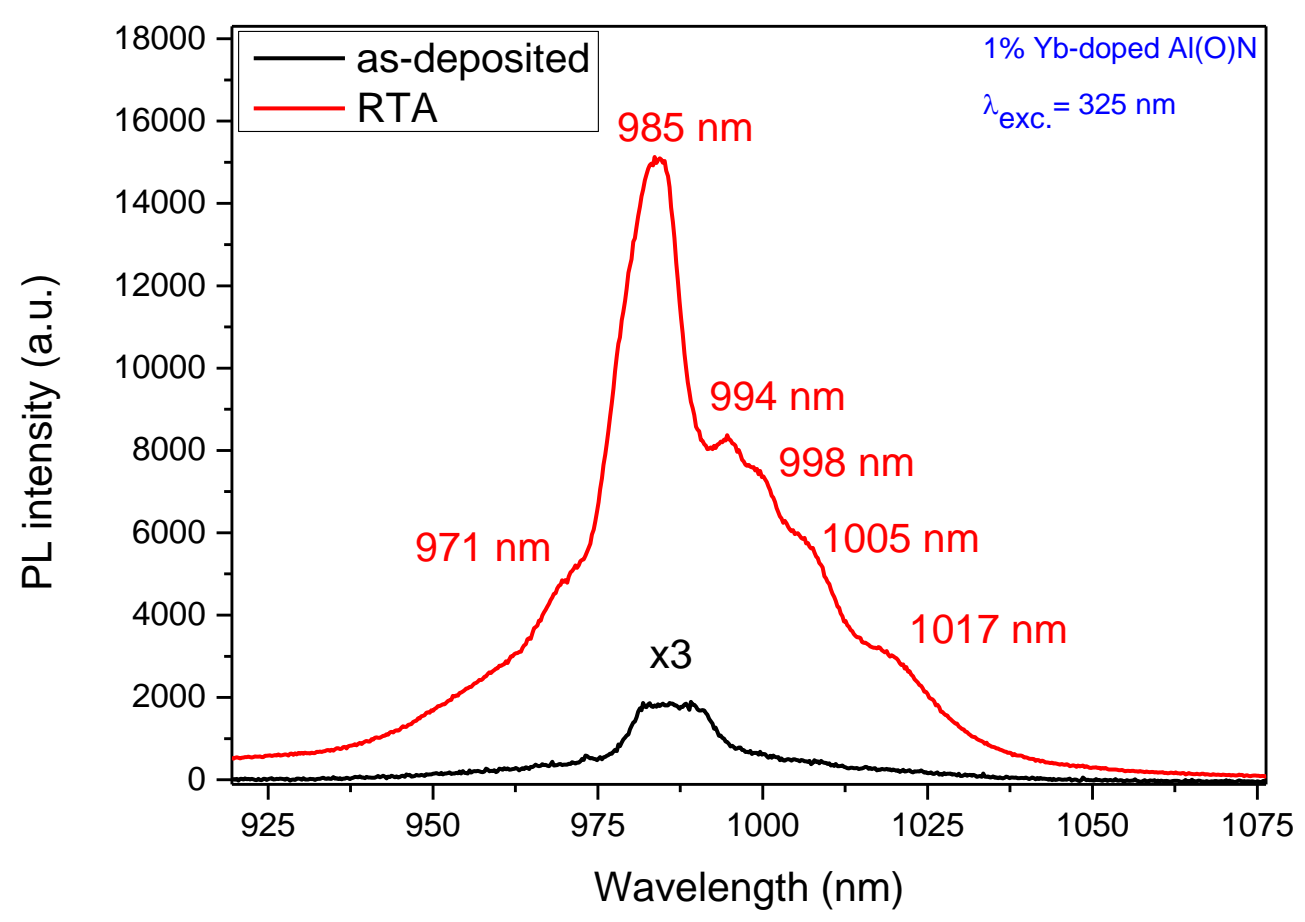


Figure 5

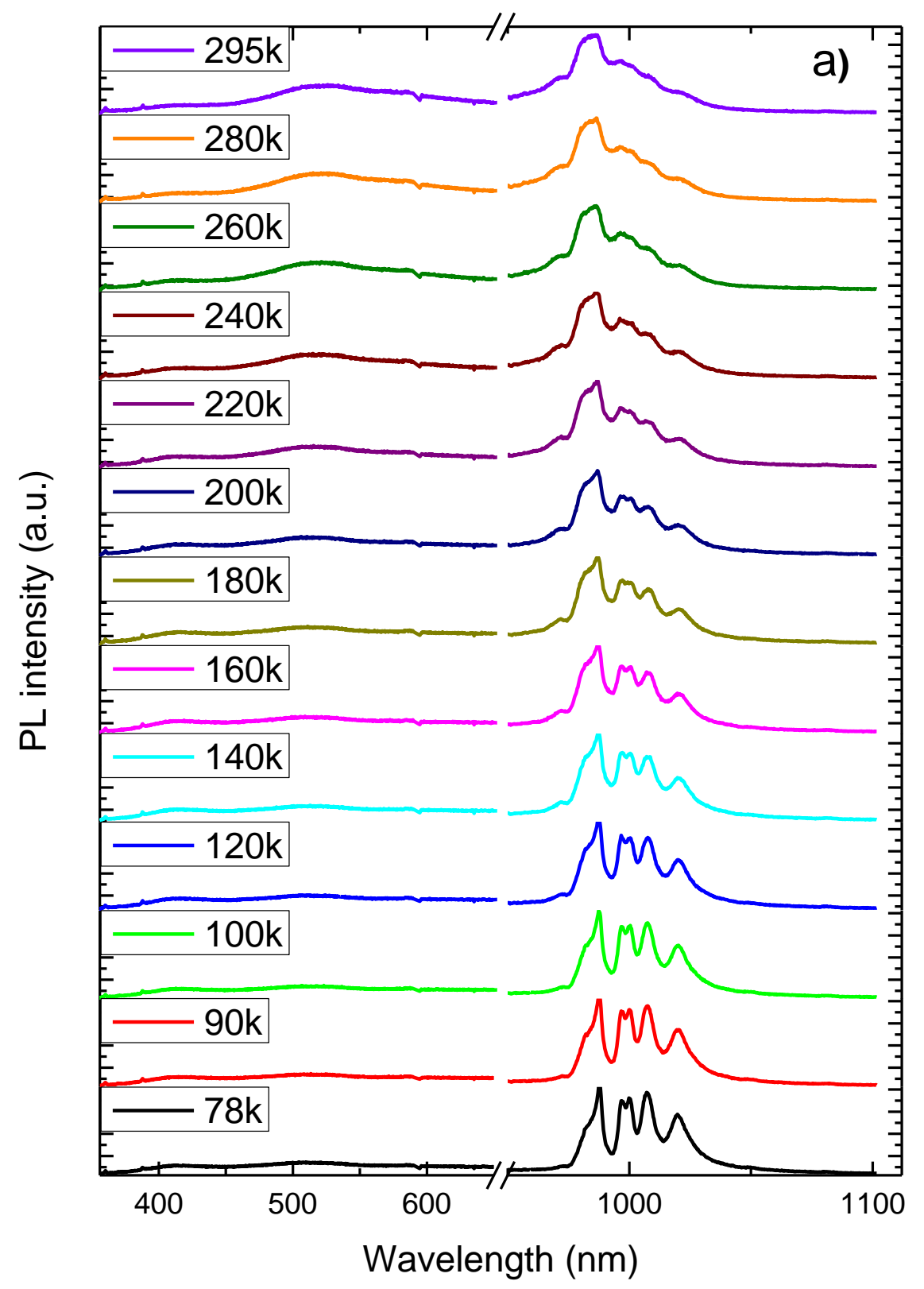




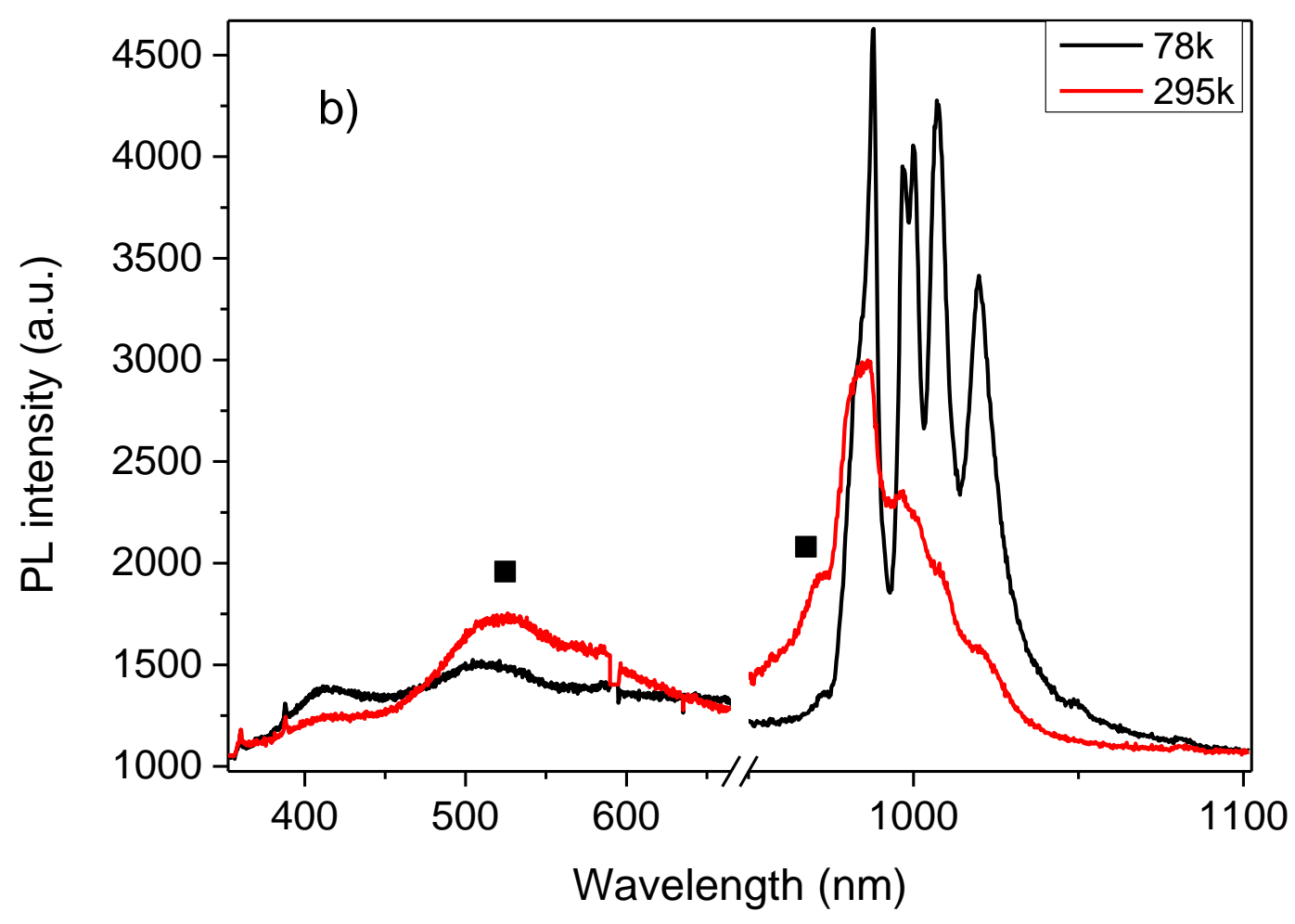


Figure 6

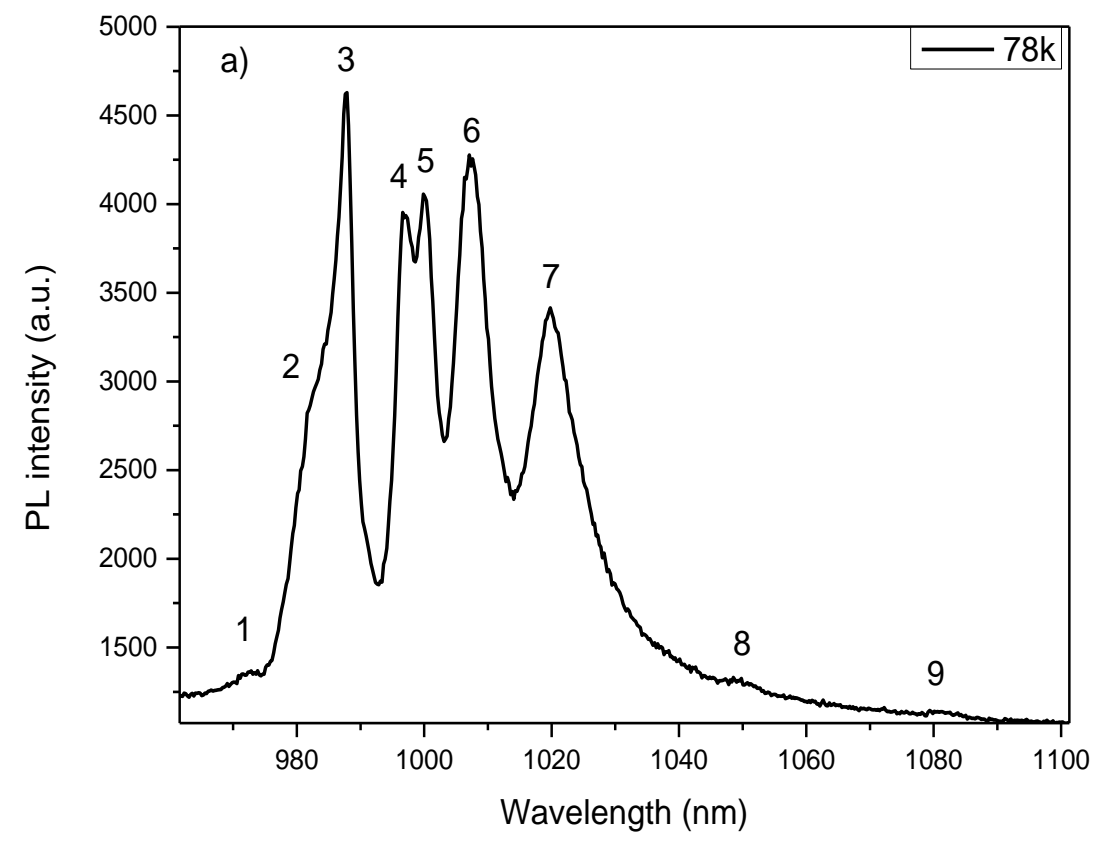


b)

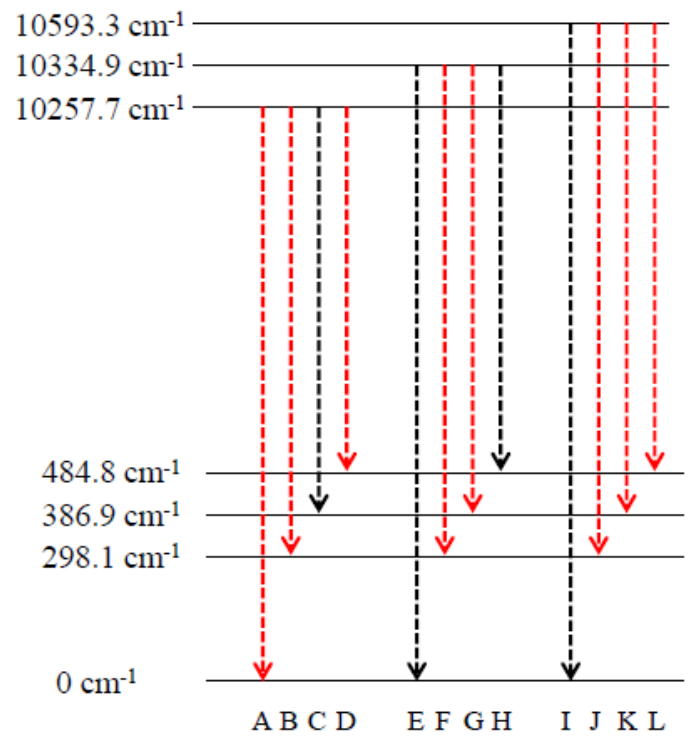

Table I: Calculated transitions and measured PL lines (in $\mathrm{nm}$ ) for $\mathrm{Yb}^{3+}$ ions in $\mathrm{Al}$ substitutional sites $\mathrm{Yb}_{\mathrm{Al}}$

\begin{tabular}{|c|c|c|}
\hline Transition label & $\begin{array}{l}\text { Calculated } \\
\text { transition, [28] }\end{array}$ & $\begin{array}{l}\text { Measured PL } \\
\text { positions in the } \\
\text { present study } \\
\text { (peak no.) }\end{array}$ \\
\hline A & 974 & $972.2(1)$ \\
\hline B & 1002.9 & $999.8(5)$ \\
\hline C & 1013 & -ב- \\
\hline D & 1023.23 & $1019.7(7)$ \\
\hline $\mathrm{E}$ & 967 & -ב- \\
\hline $\mathrm{F}$ & 995.2 & $996.6(4)$ \\
\hline G & 1005.22 & $1007(6)$ \\
\hline $\mathrm{H}$ & 1013 & (-...- \\
\hline I & 943.9 & (-ב-ב-ב \\
\hline J & 970 & $972.2(1)$ \\
\hline K & 979 & $981.7(2)$ \\
\hline $\mathrm{L}$ & 989 & $987.7(3)$ \\
\hline
\end{tabular}


Figure 7
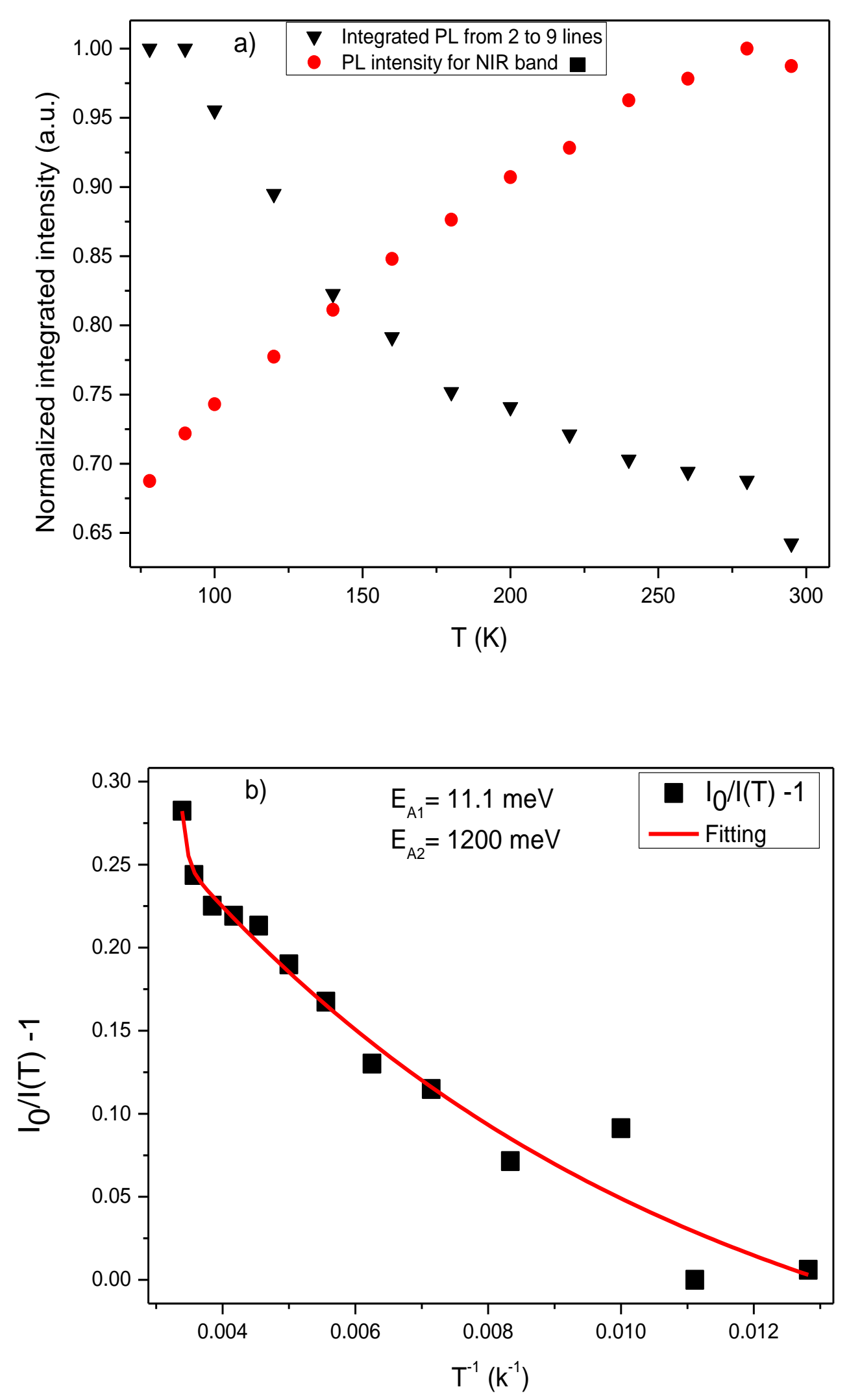
Figure 8

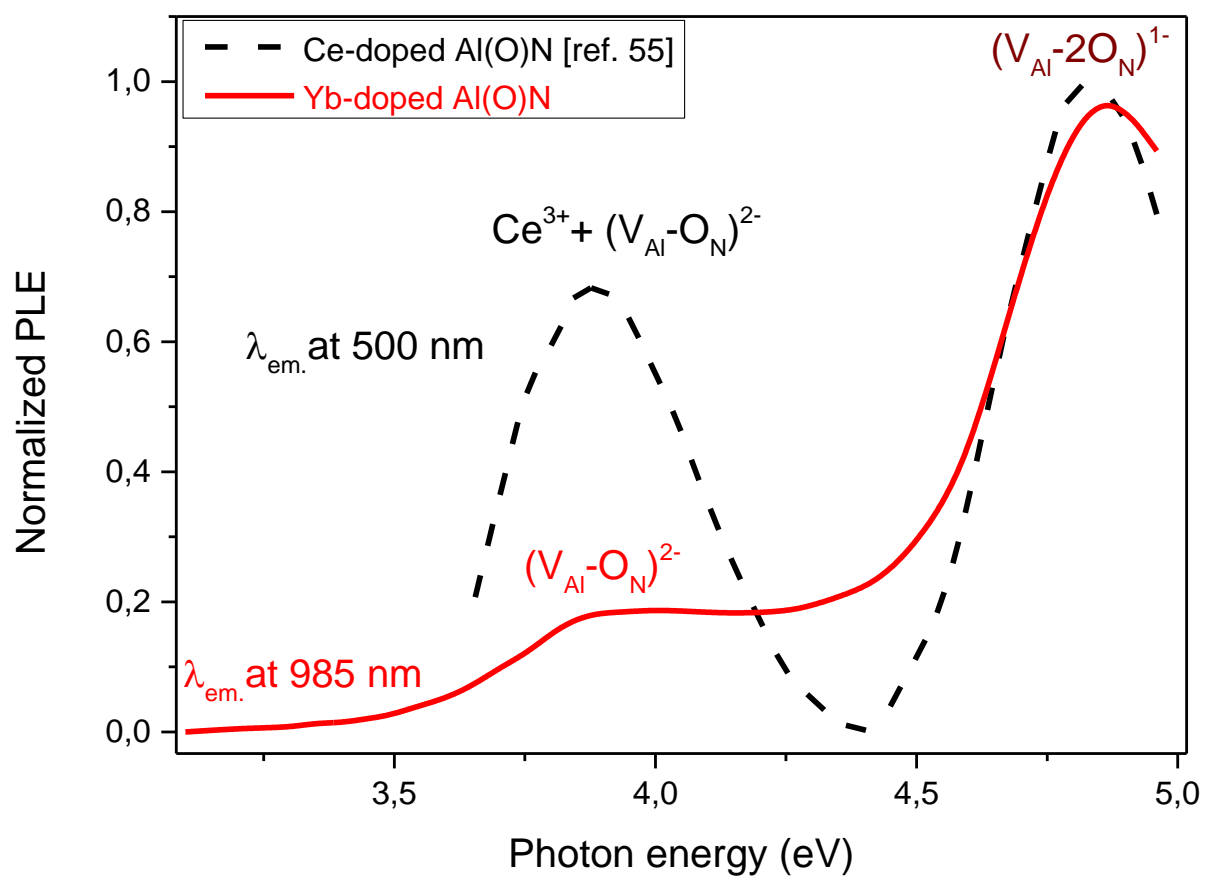


Figure 9

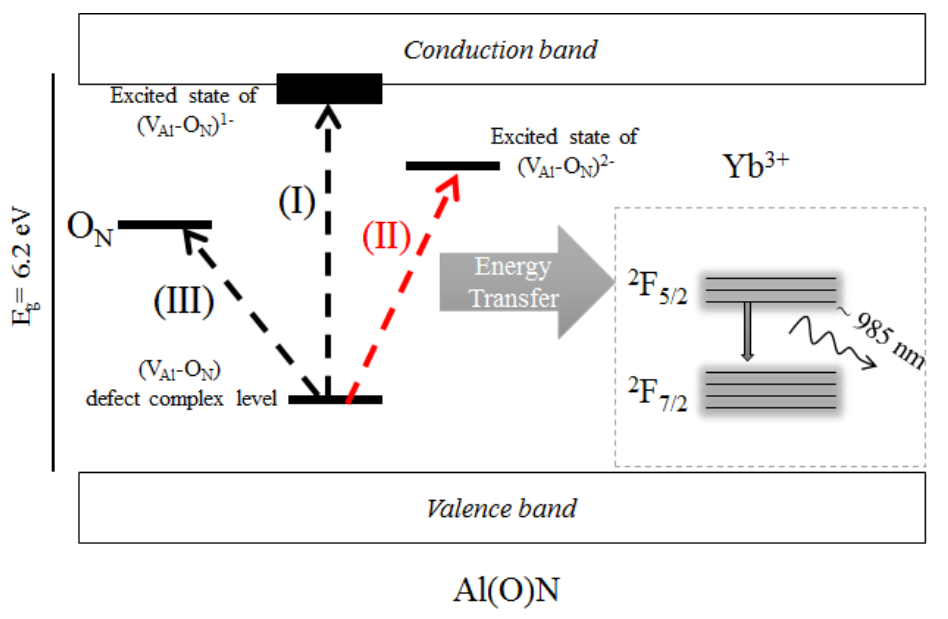

